\title{
Study of angiographic association of atherosclerotic renal artery stenosis with coronary artery disease in Bangladesh
}

\author{
Md. Sirajul Islam¹, Manzoor Mahmood¹, K.M.H.S. Sirajul Haque1, Md. Abu Siddique1, \\ Sajal Krishna Banerjee1, M. Nazrul Islam¹, Sayed Ali Ahsan1, Fazlur Rahman', \\ Chaudhury Meshkat Ahmed¹, Md. Safiuddin'1, A.T.M Iqbal Hasan¹, Md. Khurshed Ahmed \\ and Bikas Subedi. ${ }^{1}$ \\ ${ }^{1}$ Department of Cardiology, Bangabandhu Sheikh Mujib Medical University, Shahbag, Dhaka. \\ Address for Correspondence \\ Dr. Md. Sirajul Islam, Medical Officer, Department of Cardiology, UCC, Bangabandhu Sheikh Mujib Medical University, \\ Shahbag, Dhaka. \\ E-mail : md.sir@yahoo.com
}

\begin{abstract}
This retrospective observational study aimed to see the angiographic association of atherosclerotic renal-artery stenosis (ARAS) with coronary artery disease in Bangladesh. It was conducted in department of cardiology, University Cardiac Centre, Bangabandhu Sheikh Mujib Medical University, Dhaka from January2007 to January2008. A total of 250 patients with coronary artery involvement, on non-emergent coronary angiogram who underwent either selective or nonselective renal angiography were enrolled in this study. Among 250 patients, 52 (20.8\%) patient had single vessel disease (SVD), 49 $(19.6 \%)$ and149 (59.6\%) had double vessel disease (DVD) and triple vessel disease (TVD) respectively. ARAS was detected in $37.2 \%$ or 93 patients. ARAS tends to increase with age. In age group of 30-40, ARAS is $7.4 \%$ whereas in age group of 51-60 years it is $41 \%$. The incidence of ARAS is high in $50.25 \pm 9.98$ years; $\mathrm{p}=0.0001 .33 .3 \%$ male patients with CAD had ARAS whereas it was $44.3 \%$ in female patients with CAD. ARAS is more common in female $44.3 \% \mathrm{vs} 33.3 \%$; $\mathrm{p}=0.02$. ARAS prevalence increased with the number of stenosed coronary arteries (3.8\% in 1-vessel, 26.5\%in 2- vessel, 52.3\%in 3 -vessel CAD; $p=.0001$.). Hypertension and angiographically proven CAD were independent predictors of ARAS $(\mathrm{p}=0.0001)$. In conclusion, ARAS prevalence and severity increases with the number of arterial territories involved and CAD severity. Hypertension and 2-3-vessel-CAD were identified independent predictors of ARAS.
\end{abstract}

\section{Introduction}

Primary diseases of the renal arteries often involve the large renal arteries, whereas secondary diseases are frequently characterized by small-vessel and intra-renal vascular disease. Two most common primary diseases of the renal arteries are atherosclerotic renal-artery stenosis (ARAS) and fibromuscular dysplasia. ${ }^{1}$

Fibromuscular dysplasia tends to affect girls and woman between 15 and 50 years of age, frequently involves the distal two thirds of the renal artery and its branches and accounts for less than 10 percent of cases of renal artery stenosis. Atherosclerosis accounts for 90 percent of cases of renal-artery stenosis and usually in older age (after 50 years of age), more in female, usually involves ostium and proximal third of the main renal artery and the perirenal aorta and usually associated with PVD, aortoiliac occlusive disease, Diabetes, Coronary artery disease, or Hypertension. ${ }^{1-8}$

There prevalence of ARAS increases with age, in patients with known or suspected coronary artery disease, hypertension, peripheral vascular disease. 9,10
ARAS is associated with two common clinical syndromes, hypertension and ischemic nephropathy and with premature cardiovascular events (myocardial infarction, stroke, and death), and the presence of ARAS in patients with coronary disease independently doubles a patient's risk of mortality even when coronary revascularization is performed. ${ }^{11}, 12$

Noninvasive evaluation may include studies to assess overall renal function, physiological studies to assess the renin-angiotensin system, perfusion studies to assess differential renal blood flow, and imaging studies to identify renal-artery stenosis. ${ }^{13-15}$ Invasive Evaluation, contrastenhanced angiography( Renal Arteriography) are to confirm the diagnosis and cause of renal-artery stenosis and to evaluate the extent of intra-renal vascular disease, determine the dimensions of the kidneys, and identify associated aneurysmal or occlusive diseases of the aorta. ${ }^{16}$

The aim of this study was to see the association of ARAS with coronary artery disease (CAD) in Bangladeshi perspective. 


\section{Material and methods:}

This retrospective observational study was done in the department of cardiology, University Cardiac Centre, Bangabandhu Sheikh Mujib Medical University, Dhaka from January2007 to January2008. A total of 250 patients with coronary artery involvement who underwent either selective or nonselective renal angiography were enrolled in this study.

Selective angiography was performed by a right Judkins coronary catheter with hand injection of nonionic contrast agent in each main and accessory renal artery and with supplementary semi selective injections if needed. Nonselective angiography, when utilized, was performed by powered injection nonionic contrast agent through a pigtail catheter positioned at the level of the L1 vertebral body in the postero-anterior projection. All images were recorded digitally at 30 frames/s. Digital subtraction was reserved for cases with poor visualization of the renal artery due to overlying gas or structures.

Each operator categorically graded main and proximal renal arteries as normal or abnormal (any roughening or stenosis consistent with atherosclerosis) and according to stenosis location (aorto-ostial or other).

Inclusion criteria: Presence of coronary artery disease on coronary angiogram.

Exclusion criteria: Patients with normal epicardial coronary artery.

\section{Results:}

The age range of the study patients was $30-80$ years with mean age of 53.4 \pm 9.7 years. 204(81.6\%) patients were male and 46(18.4\%) were female. Baseline demographic characteristics are mentioned in the following table.

Table-I: Baseline demographic characteristics

\begin{tabular}{ccc}
\hline & Parameters & Features \\
\hline Age & Mean age & $53.4 \pm 9.7$ years \\
& Range & $30-80$ years \\
Sex & Male & $204(81.6 \%)$ \\
& Female & $46(18.4 \%)$ \\
\hline
\end{tabular}

Table-II: Risk factors profile of study population:

\begin{tabular}{ccc}
\hline Risk factors & Number & Percent \\
\hline Hypertension & 218 & 87.2 \\
Diabetes & 88 & 35.2 \\
Smoker & 49 & 19.6 \\
Dyslipidaemia & 64 & 25.6 \\
Stable angina & 155 & 62.0 \\
Unstable angina & 27 & 10.8 \\
NSTEMI & 1 & 0.4 \\
STEMI & 67 & 26.8 \\
\hline
\end{tabular}

Table-II shows the commonest risk factor was hypertension $87.2 \%$ followed by Stable angina pectoris $62 \%$.

Table -III: Frequency of ARAS in different age group.

\begin{tabular}{ccc}
\hline \multirow{2}{*}{ Age of the patient } & \multicolumn{2}{c}{ Renal angiogram } \\
\cline { 2 - 3 } & ARAS & Percent \\
\hline $30-40$ & 7 & 7.42 \\
$41-50$ & 24 & 25.40 \\
$51-60$ & 41 & 44.40 \\
$61-70$ & 15 & 16.33 \\
$71-80$ & 6 & 6.45 \\
\hline
\end{tabular}

Table-III shows ARAS tends to increase with age. In age group of $30-40$,ARAS is $7.4 \%$ whereas in age group of 5160 years it is $41 \%$. The incidence of ARAS is high in $50.25 \pm 9$.98years; $\mathrm{p}=0.0001$.

Table-IV: Frequency of ARAS in different sex group.

\begin{tabular}{cccc} 
& \multicolumn{2}{c}{ Renal angiogram } & \\
\cline { 2 - 3 } $\begin{array}{l}\text { Sex of the } \\
\text { patient }\end{array}$ & ARAS & Normal & Total number \\
\hline Male & $68(33.3 \%)$ & $136(66.7 \%)$ & 204 \\
Female & $25(44.3 \%)$ & $21(45.7 \%)$ & 46 \\
\hline
\end{tabular}

Table-IV shows $33.3 \%$ male patients with CAD had ARAS whereas it was $44.3 \%$ in case of female patients with CAD. ARAS is more common in female $44.3 \%$ vs. $33.3 \%$; $p=.02$

Figure-1: Pattern of coronary artery involvement:

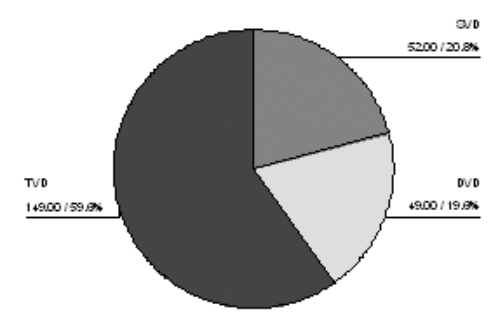

Pie chart shows $20.8 \%$ (52) patient had single vessel disease (SVD), 19.6\%(49) had double vessel disease (DVD) and 59.6\%(149) had triple vessel disease (TVD).

Table-V: Pattern of Renal artery involvement:

\begin{tabular}{ccc}
\hline Renal angiogram & Frequency & Percent \\
\hline Right renal artery stenosis & 46 & 18.4 \\
Left renal artery stenosis & 26 & 10.4 \\
Both right \&left renal artery & 21 & 8.4 \\
stenosis & 93 & 37.2 \\
Renal artery involvement & 157 & 62.8 \\
normal &
\end{tabular}

Table-V shows the anatomic pattern of renal artery involvement that had ARAS. $37.2 \%$ or 93 patients out of 
250 patients had ARAS in the form of either right renal artery stenosis or left or both.

Table-VI : Association of ARAS with CAD:

\begin{tabular}{lll}
\hline Coronary angiography & \multicolumn{2}{c}{ Renal } \\
& \multicolumn{2}{c}{ angiogram } \\
\cline { 2 - 3 } & ARAS & Normal \\
\hline SVD & $2(3.8 \%)$ & $50(96.2 \%)$ \\
DVD & $13(26.5 \%)$ & $36(73.5 .3 \%)$ \\
TVD & $78(52.3 \%)$ & $71(47.7 .2 \%)$ \\
\hline
\end{tabular}

Table-VII shows ARAS tends to increase with the severity of CAD (3.8\% in 1-vessel, 26.5\%in 2- vessel, 52.3\%in 3vessel CAD $(p=0.0001)$

\section{Discussion:}

Atherosclerotic renal artery stenosis accounts for 90 percent cases of renal-artery stenosis and associated with common clinical syndromes, hypertension and ischemic nephropathy and with premature cardiovascular events (myocardial infarction, stroke, and death) ${ }^{1,11}$., The prevalence of ARAS increases with age, particularly in patients with diabetes, aortoiliac occlusive disease, coronary artery disease, or hypertension. ${ }^{3-9}$.

The characteristics of the two different entities, fibromuscular dysplasia and atherosclerotic renal artery stenosis are mentioned in the following table:

Table-IX: Renal Artery Stenosis (RAS)

\begin{tabular}{|l|l|l|}
\hline & $\begin{array}{l}\text { Fibromuscular } \\
\text { dysplasia }\end{array}$ & $\begin{array}{l}\text { Atherosclerotic renal } \\
\text { artery stenosis(ARSA) }\end{array}$ \\
\hline Age & $\begin{array}{l}\text { Younger age } \\
\text { between } 15 \text { to } \\
50 \text { years }\end{array}$ & $\begin{array}{l}\text { Usually older age, after 50 } \\
\text { years of age }\end{array}$ \\
\hline Sex & $\begin{array}{l}\text { Girls and women } \\
\text { common }\end{array}$ & Female>Male \\
\hline $\begin{array}{l}\text { Site of renal } \\
\text { artery } \\
\text { involvement }\end{array}$ & $\begin{array}{l}\text { Distal two thirds of } \\
\text { the renal artery and } \\
\text { its branches. }\end{array}$ & $\begin{array}{l}\text { Ostium and proximal } \\
\text { third of the main renal } \\
\text { artery and the perirenal } \\
\text { aorta. }\end{array}$ \\
\hline $\begin{array}{l}\text { Associate } \\
\text { Feature }\end{array}$ & None & $\begin{array}{l}\text { PVD, aortoiliac occlusive } \\
\text { disease, Diabetes } \\
\text { coronary artery discase, or } \\
\text { hypertension. }\end{array}$ \\
\hline Prevalence & $\begin{array}{l}\text { <10\% of cases of } \\
\text { RAS }\end{array}$ & \begin{tabular}{l} 
90\%of cases of RAS \\
\hline
\end{tabular}
\end{tabular}

A correlation between coronary disease burden and the prevalence of RAS has already been established. ${ }^{7-9}$. This study demonstrates the angiographic association of RAS in patients with coronary artery disease in Bangladesh.

Older age was strongly and independently associated with RAS, implying delayed development or slower progression of atherosclerosis in renal compared with coronary and other peripheral vascular territories. In this study, incidence of ARAS is high in $50.25 \pm 9.98$ years of age $(p=0.0001)$. The incidence of ARAS declined after the age of 60 years in our study was probably due to small number of sample size. In Weber-Mzell et al. ${ }^{11} 2002$ study, patients with ARAS were older $(67 \pm 8$ years, $P=0.004)$, whereas in Buller et. al. ${ }^{9}$ showed 73.2 years $(\mathrm{p}=0.001)$.

In our study, ARAS is more common in female gender $44.3 \%$ vs33.3\%; $\mathrm{p}=.02$ which is similar to Buller et al. ${ }^{9}$, $13 \%$ vs. $6 \%, \mathrm{p}=0.001$.

Coronary disease burden was observed to have an important association with RAS which was consistent with other study. We found the prevalence ARAS was substantially higher in subgroups defined by CAD. $37.2 \%$ patients with CAD had ARAS in the form of either right renal artery stenosis or left or both. In Jean et al. ${ }^{7}$ study, it was 34\% and in Przewlocki et al. ${ }^{8}$ study it was $35.4 \%$. ARAS prevalence increased with the number of stenosed coronary arteries. In this study, it showed the similar trend. ARAS prevalence in-terms of coronary artery involvement were, $3.8 \%$ in 1 vessel, $26.5 \%$ in 2 - vessel, $52.3 \%$ in 3 -vessel CAD, $\mathrm{p}=0.0001$.Przewlocki et. al. ${ }^{8}$ study revealed ARAS prevalence $(38.4 \%$ in 1 -vessel, $42.1 \%$ in 2 -vessel, $48.5 \%$ in 3 vessel CAD, $P<0.001)$.

In this study, the commonest risk factor was hypertension $(87.2 \%)$ followed by Stable angina pectoris $(62 \%)$. Other risk factors are diabetes mellitus (35.2\%), Smoking (19.6\%), Dyslipidaemia (25.6\%). Logistic regression analysis of independent predictors of ARAS revealed Hypertension and extent of CAD were independent predictors of ARAS which was consistent with Weber-Mzell et. al. ${ }^{11}$ and Przewlocki et. al. ${ }^{8}$ study.

\section{Conclusion:}

ARAS prevalence and severity increases with the number of arterial territories involved. CAD severity and hypertension was identified as independent predictor of ARAS. As poor prognosis is independently associated with the presence of ARAS, it is needed to identify ARAS as early as possible. It is reasonable to perform screening renal Arteriography at the time of cardiac catheterization in patients with more than 2 diseased coronary segments.

\section{References:}

1. Safian RD, Textor SC. Renal-artery stenosis. N Engl J Med 2001; 344: 431-42.

2. Scoble JE. The epidemiology and clinical manifestations of atherosclerotic renal disease. In: Novick AC, Scoble JE,Hamilton G,eds. Renal Vascular Disease. London, England: WB Saunders; 1996:303-14.

3. Sawicki PT, Kaiser S, Heinemann I, Frenzel H, Berger M. Prevalence of renal artery stenosis in diabetes mellitus - an autopsy study. Ann Intern Med 1991; 229:489-92.

4. Dean RH, Kieffer RW, Smith BM, et al. Renovascular 
hypertension: anatomic and renal function changes during therapy. Arch Surg. 1981; 116:1408-15.

5. Tollefson DF, Ernst CB. Natural history of atherosclerotic renal artery stenosis associated with aortic disease. J Vasc Surg. 1991; 14:327-31.

6. Crowley JJ, Santos RM, Peter RH, et al. Progression of renal artery stenosis in patients undergoing cardiac catheterization. Am Heart J 1998; 136:913-18.

7. Jean WJ, al-Bitar I, Zwicke DL etal. High incidence of renal artery stenosis in patients with coronary artery disease. Cathet Crdiovasc Diagn.1994; 32:8-10.

8. Tadeusz Przewlocki, Anna Kablak-Ziembicka, Wieslawa Tracz,etal. Prevalence and prediction of renal artery stenosis in patients with coronary and supraaortic artery atherosclerotic disease. Nephrology Dialysis Transplantation 2008 23(2):580-85.

9. Christopher E. Buller, Jorge G. Nogareda, Krishnan Ramanathan, et al. The profile of cardiac patients with renal artery stenosis. J Am Coll Cardiol, 2004; 43:1606-13.

10. Christopher J. White, Michael R.Jaff, Ziv J.Haskal, et al. Indications for Renal Arteriography at the time of Coronary Arteriography.Circulation.2006;114:1892-95.

11. Weber-Mzell, D., Kotanko, P., Schumacher, M., Klein, W.
Skrabal, F. (2002), Coronary anatomy predicts presence or absence of renal artery stenosis. A prospective study in patients undergoing cardiac catheterization for suspected coronary artery disease. Eur Heart J 23: 1684-91

12. Peter L, Robert OB, Douglas LM, Douglas PZ, Eugene B. Systemic hypertension: Mechanism and Diagnosis.In: Zipes DP,Libby P, Bonow RO, (eds.) Braunwald's Heart Disease. $8^{\text {th }}$ ed, Philadelphia: Saunders, 2007; 1039-40.

13. Setaro JF, Chen CC, Hoffer PB, Black HR. Captopril renography in the diagnosis of renal artery stenosis and the prediction of improvement with revascularization: the Yale Vascular Center experience. Am J Hypertens 1991; 4:698S705S-698S-705S.

14. Hansen KJ, Tribble RW, Reavis SW, et al. Renal duplex sonography: evaluation of clinical utility. J Vasc Surg 1990; 12:227-36

15. Gedroyc WMW, Neerhut P, Negus R, et al. Magnetic resonance angiography of renal artery stenosis. Clin Radiol 1995; 50:436-39.

16. Kaufman JA, Geller SC, Waltman AC. Renal insufficiency: gadopentetate dimeglumine as a radiographic contrast agent during peripheral vascular interventional procedures. Radiology 1996;198:579-81 